The results in the cases shown to-night were similar to those claimed for creosote in the primary cases of pulmonary tuberculosis. If we could only relieve the distressing symptoms of these patients, we were doing much.

\title{
SIXTY-SIXTH CONGRESS OF GERMAN NATURALISTS AND PHYSICIANS, VIENNA.
}

\author{
Addendum by Dr. B. GOMPERTz ("Monatsschrift fïr Ohrenheilkunde"),
}

Although the reports of the discussions were taken from the manuscripts handed in by the speakers, Drs. Reinhard and Scheibe are desirous of making an addition to their remarks, for which we willingly find room.

These remarks have reference to the discussion upon my paper "On the Results of a Conservative Method of Treatment in Chronic Suppuration of the Upper Cavities of the Tympanum." Our confrire REINHARD draws my attention to the fact that the sentence beginning with the remarks (JOURNAL OF LARYNGOLOGY, April, 1895, p. 323) "Suppurations "limited to the attic were, in Schwartze's clinic, treated in the conservative "way," would be more accurately expressed to the effect that "not all "cases of attic suppuration were from the outset treated by operative "methods; that he had seen cases at Halle, in which the suppuration " was entirely cured by means of irrigation with the tympanic catheter. "Such cases were, however, rare, and in by far the larger majority there

"was associated an implication of the antrum of the nature of caries, or

" of cholesteatoma formation, which ought only to be treated by operative

"measures, and this owing to the great danger to life which the condition "threatened."

Dr. SCHEIBE wishes the meaning of the short report of his remarks (Journal of LARYNGOLOGY, April, I895, p. 323) to be rectified in the following way: "Scheibe has treated about sixty cases of chronic middle" ear suppuration with cholesteatoma formation in the upper tympanic "cavities, and in about fifty per cent. a cure was effected by simple con-

"servative means. On the occurrence of serious symptoms, such as "periostitis, etc., as also particularly in those cases in which the foetor "does not disappear under continued conservative treatment, he insists "upon a permanent free opening being made into the upper tympanic "chamber. ... He insists further that a comparison between the "results of the conservative method and those of the operative (extraction " of the ossicles) can only be made when the diseased condition in both "cases is identical from the outset. Injection and insufflation with the "tympanic tube should only be employed in cholesteatoma of the upper "tympanic chambers; extraction of the ossicles, on the other hand, in "other suppurations of the middle ear."

Prof. Gruber desires to say that Prof. Politzer's remarks were not a direct contradiction of his, as would appear from the report, but that 
Prof. Politzer mentions that in one such case a certain amount of hearing power was present.

Prof. POLITZER desired to correct the remarks made by Prof. Habermann in the discussion upon the administration of his preparations illustrating a primary disease of the capsule of the labyrinth, in so far as Prof. Habermann had not stated in the discussion that he disagreed with Prof. Politzer's opmion as to the interpretation of the appearances, otherwise Prof. Politzer would have given his reasons in support of his views contrary to those of Prof. Habermann in the discussion.

[We are glad to be able to reproduce the above remarks, because to those who have taken a serious interest in the discussions at this important congress these expressions of the after thoughts of the speakers cannot but be of the greatest value. Remarks uttered during the hurry and excitement of a meeting do not always render so clearly as might be desired the exact ideas which the speaker really wishes to convey, and this without any imputation on the honesty or accuracy of either speaker or reporter.-ED.]

Dundas Grant, Trans.

\section{PROCEEDINGS of the LARYNGOLOGICAL SOCIETY of LONDON.}

Ordina'y Meeting, December $12 t h$, 1894 .

Double Abductor Paralysis of Uncertain Origin, associated with Cystic Bronchocele and Dyspnae; Operation; Improvement.

Mr. A. A. BowlBy showed a patient, a man aged sixty, who was admitted into St. Bartholomew's Hospital on March 17th, 1894, on account of dyspncea and bronchocele.

He said that the enlargement of the thyroid gland had existed for about two years; that for about three months he had suffered from some difficulty in swallowing, and for a month from difficulty in breathing. He had had several attacks of sudden and urgent dyspnœa.

Examination showed a very large thyroid cyst, situated on the left side of the neck, and about as large as a cocoanut. The larynx and trachea were a good deal displaced to the right of the middle line. The thyroid gland was not itself hypertrophied to any appreciable extent. Voice not affected, except that it was not strong; swallowing decidedly difficult and slow. Laryngoscopic examination showed double abductor paralysis, the cords not separating in respiration more than one-eighth of an inch.

On March 22nd the cyst was removed by operation without trouble, and the wound healed throughout by first intention. The dyspnoa and dysphagia were immediately relieved, and three weeks later the patient was discharged. He had one slight attack of dyspnœa a few days afterwards, but since then had had no return of such attacks. 